\title{
Ab initio Study of the Spin Density of Nitroxide Radicals*
}

\author{
Jiahu Wang and Vedene H. Smith, Jr. \\ Department of Chemistry, Queen's University, Kingston, Ontario, Canada
}

Z. Naturforsch. 48a, 109-116 (1993); received July 4, 1992

The spin densities of the nitroxides $\mathrm{H}_{2} \mathrm{NO},\left(\mathrm{CH}_{3}\right) \mathrm{HNO}$ and $\left(\mathrm{CH}_{3}\right)_{2} \mathrm{NO}$ have been studied by iterative $\mathrm{CI}$ methods. Calculations at different geometries with various basis sets were performed. It is found that the spin distribution is delocalized within the $\mathrm{N}-\mathrm{O}$ group, and substitution of the hydrogen atoms on the nitroxyl group by methyl groups changes the spin distribution significantly. Electron correlation, as well as the basis-set quality, plays an important rôle for the fluctuation of spin populations in the nitroxide radicals. It has been found that the spin density map can be predicted fairly well when correlation was included at certain levels and reasonable quality basis sets were employed. The spin polarization mechanism has been studied through a core excitation method. The superiority of local-spin-density (LSD) theory over the unrestricted Hartree-Fock (UHF) method in spin property studies is discussed.

Key words: Spin density; Nitroxide radicals; Iterative CI; Spin polarization effect; LDA.

\section{Introduction}

Nitroxide radicals are especially stable and have been studied extensively by ESR [1-3] and recently by the polarized-neutron diffraction (PND) technique [4]. The spin densities on the nuclei with non-zero spins are accessed through the measurement of isotropic coupling constants in the ESR spectra. PND, on the other hand, through Fourier summation of the magnetic structure factors, not only provides the spin density on nuclear centres, but also in the space over the whole molecules. This renews interest in the theoretical study of this species. Earlier reported results include work conducted by Ellinger and collaborators [5-9] and others [10, 11]. A variety of methods, including UHF, PUHF [5], conventional CI methods and double perturbation theory (DPT) [7], were employed to calculate the spin distribution. The spin densities on the nitrogen and hydrogen nuclei could be predicted in very close agreement with the ESR data using the DPT and CI methods with small basis sets; however, the predicted spin partition between $\mathrm{N}$ and $\mathrm{O}$ is far from the experiment. The strong localization of spin on the oxygen is in contradiction with the PND measurement [4] which reveals an almost

* Presented at the Sagamore X Conference on Charge, Spin and Momentum Densities, Konstanz, Fed. Rep. of Germany, September 1-7, 1991.

Reprint requests to Prof. V. H. Smith, Jr., Department of Chemistry, Queen's University, Kingston, Ontario, K7L 3N6, Canada. equally distributed spin density between the nitrogen and oxygen atoms.

Delley et al. [11] applied the local spin density (LSD) theory to a few simple nitroxides and obtained a quite satisfactory account of the spin distribution in these radicals. However, their conclusions on basis set and electron correlation effects are open to question. They employed an exchange-only LSD theory as well and found no significant changes in the spin properties from those when the correlation potential was included. This greatly puzzled theoreticians in this field, as shown in two recent reviews by Becker [12], and by Gillon and Schweizer [13].

In the present work, we report our systematic study of the basis sets, electron correlation as well as geometry effects on the spin distribution in nitroxides. The CI calculations were based on a restricted open-shell Hartree-Fock (ROHF) reference. The iterative CI method with natural orbitals [14] was used to account for the higher-excitation effects and to rectify the poorness of the ROHF reference. The higher-excitation effects were studied with the CISDTQ technique as well. Hartree atomic units are used throughout this report.

\section{Details of Computation}

The SCF-CI computations used the MELD program [15] on an IBM RISC/6000/320 work station. Clementi's $7 \mathrm{~s} 3 \mathrm{p} / 3 \mathrm{~s}$ and its contracted form $3 \mathrm{~s} 2 \mathrm{p} / 1 \mathrm{~s}$ basis sets [16] and the $6-31 \mathrm{G}$ series 
Table 1. Geometrical parameters of $\mathrm{H}_{2} \mathrm{NO},\left(\mathrm{CH}_{3}\right) \mathrm{HNO}$ and $\left(\mathrm{CH}_{3}\right)_{2} \mathrm{NO}$ used in the calculations.

\begin{tabular}{lrrr}
\hline & \multicolumn{1}{c}{$X$} & $Y$ & $Z$ \\
\hline $\mathrm{H}_{2} \mathrm{NO}$ & & & \\
$\mathrm{N}$ & 0.00 & 0.00 & 0.00 \\
$\mathrm{O}\left(C_{2 \mathrm{v}}\right)$ & 2.44 & 0.00 & 0.00 \\
$\quad\left(C_{s}\right)$ & 2.35 & 0.00 & 0.66 \\
$\mathrm{H}$ & -0.86 & \pm 1.67 & 0.00 \\
$\left(\mathrm{CH}_{3}\right) \mathrm{HNO}$ & & & \\
$\mathrm{N}$ & 0.00 & 0.00 & 0.00 \\
$\mathrm{O}$ & 2.44 & 0.00 & 0.00 \\
$\mathrm{H}_{a}$ & -0.86 & 1.67 & 0.00 \\
$\mathrm{C}$ & -1.30 & -2.52 & 0.00 \\
$\mathrm{H}_{b}$ & -3.28 & -2.24 & 0.00 \\
$\mathrm{H}_{c}$ & -0.77 & \pm 3.54 & \pm 1.63 \\
$\left(\mathrm{CH}_{3}\right)_{2} \mathrm{NO}$ & & & \\
$\mathrm{N}$ & & & \\
$\mathrm{O}_{\mathrm{C}}$ & 0.00 & 0.00 & 0.00 \\
$\mathrm{H}_{\alpha}$ & 2.44 & 0.00 & 0.00 \\
$\mathrm{H}_{b}$ & -1.30 & \pm 2.52 & 0.00 \\
\hline
\end{tabular}

(6-31G [17], and 6-31G** [18]) were used. The experimental geometries of $\mathrm{H}_{2} \mathrm{NO},\left(\mathrm{CH}_{3}\right) \mathrm{HNO}$ and $\left(\mathrm{CH}_{3}\right)_{2} \mathrm{NO}$ were deduced from tanol suberate (di-4-(2,2,6,6-tetramethyl-piperidinyl-1-oxide) suberate. $\left.\left(\left(\mathrm{CH}_{3}\right)_{4} \mathrm{C}_{5} \mathrm{H}_{5} \mathrm{NO}\right)_{2}\left(\mathrm{OOC}-\mathrm{C}_{6} \mathrm{H}_{12}-\mathrm{COO}\right)\right)$ and idealized to $\mathrm{C}_{\mathrm{s}}$ and $\mathrm{C}_{2 \mathrm{v}}$ as recommended by Delley et al. [11]; no further optimization was attempted. Details for the geometry are given in Table 1 .

For the SCF-CISD studies, the ROHF configuration was chosen as the starting point. Spin-adapted configurations for all the single and double excitations from the reference configuration were included. The total wavefunction is a pure spin state. In the subsequent iterative procedure, the Slater determinant wavefunction consisting of the first 9 natural spin orbitals with the highest occupation numbers replaced the ROHF wavefunction as the new reference. This provides the best-density independent-particle-model (IPM) [19-21]. The iterative CI spin properties were taken after five iterations. The total energy, spin den-

Table 2. Total energies, spin densities, Mulliken spin populations and the number of configurations for $\mathrm{H}_{2} \mathrm{NO}$ with the SDCI treatment and various basis sets.

\begin{tabular}{|c|c|c|c|c|c|c|c|c|}
\hline \multirow[t]{2}{*}{ Basis set } & \multirow[t]{2}{*}{ Total energy } & \multicolumn{3}{|c|}{ Spin density } & \multicolumn{3}{|c|}{ Mulliken spin population } & \multirow{2}{*}{$\begin{array}{l}\text { No. of con- } \\
\text { figurations }\end{array}$} \\
\hline & & $\mathrm{N}$ & $\mathrm{O}$ & $\mathrm{H}$ & $\mathrm{N}$ & $\mathrm{O}$ & $\mathrm{H}$ & \\
\hline \multicolumn{9}{|c|}{$\mathrm{C}_{2 \mathrm{v}}$ geometry } \\
\hline $\begin{array}{l}3 \mathrm{~s} 2 \mathrm{p} / 1 \mathrm{~s} \\
7 \mathrm{~s} 3 \mathrm{p} / 3 \mathrm{~s} \\
6-31 \mathrm{G} \\
6-31 \mathrm{G} * *\end{array}$ & $\begin{array}{l}-130.2424224 \\
-130.4168878 \\
-130.5525975 \\
-130.7221425\end{array}$ & $\begin{array}{l}0.1071 \\
0.0259 \\
0.0680 \\
0.0339\end{array}$ & $\begin{array}{l}0.3054 \\
0.0612 \\
0.1776 \\
0.0843\end{array}$ & $\begin{array}{l}-0.0070 \\
-0.0050 \\
-0.0081 \\
-0.0063\end{array}$ & $\begin{array}{l}0.2968 \\
0.3032 \\
0.3105 \\
0.3062\end{array}$ & $\begin{array}{l}0.7311 \\
0.7294 \\
0.7233 \\
0.7146\end{array}$ & $\begin{array}{l}-0.0139 \\
-0.0163 \\
-0.0169 \\
-0.0104\end{array}$ & $\begin{array}{r}3344 \\
23801 \\
4689 \\
23615\end{array}$ \\
\hline \multicolumn{9}{|c|}{$\mathrm{C}_{s}$ geometry } \\
\hline $\begin{array}{l}3 \mathrm{~s} 2 \mathrm{p} / 1 \mathrm{~s} \\
7 \mathrm{~s} 3 \mathrm{p} / 3 \mathrm{~s} \\
6-31 \mathrm{G} \\
6-31 \mathrm{G}^{* *}\end{array}$ & $\begin{array}{l}-130.2416677 \\
-130.4163211 \\
-130.5519433 \\
-130.7220447\end{array}$ & $\begin{array}{l}0.1150 \\
0.0340 \\
0.0744 \\
0.0423\end{array}$ & $\begin{array}{l}0.3054 \\
0.0607 \\
0.1777 \\
0.0844\end{array}$ & $\begin{array}{l}-0.0060 \\
-0.0040 \\
-0.0068 \\
-0.0050\end{array}$ & $\begin{array}{l}0.2894 \\
0.2943 \\
0.3025 \\
0.2961\end{array}$ & $\begin{array}{l}0.7352 \\
0.7343 \\
0.7276 \\
0.7210\end{array}$ & $\begin{array}{l}-0.0123 \\
-0.0143 \\
-0.0150 \\
-0.0086\end{array}$ & $\begin{array}{r}5905 \\
39775 \\
8043 \\
43341\end{array}$ \\
\hline
\end{tabular}

Table 3. Total energies, spin densities, Mulliken spin populations and the number of configurations for $\mathrm{H}_{2} \mathrm{NO}$ with the Iterative CI treatment and various basis sets.

\begin{tabular}{|c|c|c|c|c|c|c|c|c|}
\hline \multirow[t]{2}{*}{ Basis set } & \multirow[t]{2}{*}{ Total energy } & \multicolumn{3}{|c|}{ Spin density } & \multicolumn{3}{|c|}{ Mulliken spin population } & \multirow{2}{*}{$\begin{array}{l}\text { No. of con- } \\
\text { figurations }\end{array}$} \\
\hline & & $\mathrm{N}$ & $\mathrm{O}$ & $\mathrm{H}$ & $\mathrm{N}$ & $\mathrm{O}$ & $\mathrm{H}$ & \\
\hline \multicolumn{9}{|c|}{$\mathrm{C}_{2 \mathrm{v}}$ geometry } \\
\hline $\begin{array}{l}3 \mathrm{~s} 2 \mathrm{p} / 1 \mathrm{~s} \\
7 \mathrm{~s} 3 \mathrm{p} / 3 \mathrm{~s} \\
6-31 \mathrm{G} \\
6-31 \mathrm{G}^{* *}\end{array}$ & $\begin{array}{l}-130.2429003 \\
-130.4175058 \\
-130.5533062 \\
-130.7229931\end{array}$ & $\begin{array}{l}0.1305 \\
0.0351 \\
0.0846 \\
0.0452\end{array}$ & $\begin{array}{l}0.2915 \\
0.0590 \\
0.1682 \\
0.0787\end{array}$ & $\begin{array}{l}-0.0080 \\
-0.0057 \\
-0.0093 \\
-0.0073\end{array}$ & $\begin{array}{l}0.3523 \\
0.3713 \\
0.3753 \\
0.3782\end{array}$ & $\begin{array}{l}0.6795 \\
0.6661 \\
0.6637 \\
0.6458\end{array}$ & $\begin{array}{l}-0.0159 \\
-0.0187 \\
-0.0195 \\
-0.0120\end{array}$ & $\begin{array}{r}3344 \\
23801 \\
4689 \\
23615\end{array}$ \\
\hline \multicolumn{9}{|c|}{$\mathrm{C}_{s}$ geometry } \\
\hline $\begin{array}{l}3 \mathrm{~s} 2 \mathrm{p} / 1 \mathrm{~s} \\
7 \mathrm{~s} 3 \mathrm{p} / 3 \mathrm{~s} \\
6-31 \mathrm{G} \\
6-31 \mathrm{G}^{* *}\end{array}$ & $\begin{array}{l}-130.2421501 \\
-130.4169440 \\
-130.5526459 \\
-130.7229492\end{array}$ & $\begin{array}{l}0.1400 \\
0.0451 \\
0.0927 \\
0.0558\end{array}$ & $\begin{array}{l}0.2912 \\
0.0585 \\
0.1682 \\
0.0789\end{array}$ & $\begin{array}{l}-0.0068 \\
-0.0046 \\
-0.0078 \\
-0.0058\end{array}$ & $\begin{array}{l}0.3450 \\
0.3623 \\
0.3670 \\
0.3677\end{array}$ & $\begin{array}{l}0.6833 \\
0.6707 \\
0.6679 \\
0.6522\end{array}$ & $\begin{array}{l}-0.0142 \\
-0.0151 \\
-0.0174 \\
-0.0099\end{array}$ & $\begin{array}{r}5905 \\
39775 \\
8043 \\
43341\end{array}$ \\
\hline
\end{tabular}


Table 4. Total energies, spin densities, Mulliken spin populations and the number of configurations for $\left(\mathrm{CH}_{3}\right) \mathrm{HNO}$ with the SDCI and Iterative CI treatments and various basis sets.

\begin{tabular}{|c|c|c|c|c|c|c|c|c|c|c|}
\hline \multirow[t]{2}{*}{ Basis set } & \multirow[t]{2}{*}{ Total energy } & \multicolumn{4}{|c|}{ Spin density } & \multicolumn{4}{|c|}{ Mulliken spin population } & \multirow{2}{*}{$\begin{array}{l}\text { No. of con- } \\
\text { figurations }\end{array}$} \\
\hline & & $\mathbf{N}$ & $\mathrm{O}$ & $\mathbf{H}_{a}$ & $\mathrm{C}$ & $\mathbf{N}$ & $\mathrm{O}$ & $\mathrm{H}_{a}$ & $\mathrm{C}$ & \\
\hline \multicolumn{11}{|l|}{ SDCI } \\
\hline $\begin{array}{l}3 s 2 p / 1 s \\
6-31 G\end{array}$ & $\begin{array}{l}-169.2345155 \\
-169.6503757\end{array}$ & $\begin{array}{l}0.1078 \\
0.0722\end{array}$ & $\begin{array}{l}0.2698 \\
0.1555\end{array}$ & $\begin{array}{l}-0.0067 \\
-0.0076\end{array}$ & $\begin{array}{l}-0.0170 \\
-0.0114\end{array}$ & $\begin{array}{l}0.3148 \\
0.3167\end{array}$ & $\begin{array}{l}0.7081 \\
0.6997\end{array}$ & $\begin{array}{l}-0.0134 \\
-0.0154\end{array}$ & $\begin{array}{l}-0.0245 \\
-0.0256\end{array}$ & $\begin{array}{l}34933 \\
51768\end{array}$ \\
\hline \multicolumn{11}{|c|}{ Iterative CI } \\
\hline $\begin{array}{l}3 s 2 p / 1 s \\
6-31 G\end{array}$ & $\begin{array}{l}-169.2343708 \\
-169.6516509\end{array}$ & $\begin{array}{l}0.1457 \\
0.0930\end{array}$ & $\begin{array}{l}0.2524 \\
0.1428\end{array}$ & $\begin{array}{l}-0.0063 \\
-0.0090\end{array}$ & $\begin{array}{l}-0.0159 \\
-0.0135\end{array}$ & $\begin{array}{l}0.3795 \\
0.4032\end{array}$ & $\begin{array}{l}0.6427 \\
0.6145\end{array}$ & $\begin{array}{l}-0.0135 \\
-0.0183\end{array}$ & $\begin{array}{l}-0.0261 \\
-0.0316\end{array}$ & $\begin{array}{l}34933 \\
51768\end{array}$ \\
\hline
\end{tabular}

sities on the nuclear centres and Mulliken spin population of $\mathrm{H}_{2} \mathrm{NO}$ are listed in Table 2 for the SDCI wavefunction and in Table 3 for the iterative CI wavefunction. Table 4 contains the results for $\left(\mathrm{CH}_{3}\right) \mathrm{HNO}$; those for $\left(\mathrm{CH}_{3}\right)_{2} \mathrm{NO}$ are summarized in Table 5. Also shown in the tables are the total numbers of configurations in each case. In Fig. 1, the iterative CI spin density in the molecular plane of $\mathrm{H}_{2} \mathrm{NO}$ is shown. The iterative spin density in the $\pi$-plane is displayed in Figure 2. The transfer of spin density through the iterative technique is shown in Figs. 3 and 4.

\section{Results and Discussion}

\section{1. $\mathrm{H}_{2} \mathrm{NO}$}

A comparison of the results for dihydronitroxide at $\mathrm{C}_{2 \mathrm{v}}$ and $\mathrm{C}_{s}$ geometries suggests that change in the geometry does not greatly affect the spin densities. With the 6-31G basis set, the SCF treatment predicts a partition of the Mulliken spin population N/O as $0.1967 / 0.8033$ at $C_{2 v}$ and $0.1920 / 0.8070$ at $C_{s}$ geometries. The differences occur only at the third decimal place. At the CISD level, the changes are a little larger, but the reason may not be attributed to the geometry effect alone because electron correlation is included at this stage. At the same time, the densities on the centres also view larger changes at the CISD approach than those at the SCF calculation. Basically, the spin density on the nitrogen nucleus increases when the symmetry of the system is lowered, whereas those on oxygen and hydrogen nuclei decrease. The subsequent iterative CI calculation diminished these differences, and after five iterations the differences are very small. Therefore it is proposed that geometry is not an important factor as far as the spin properties are concerned. In the following studies, only the planar geom- etries were considered in order to save computing time.

The great changes in the partition of the spin population within the nitroxyl group from an SCF wavefunction to the correlated wavefunction at the CISD level clearly show the great contribution of electron correlation. The significance of electron correlation to the spin distribution is further demonstrated by the substantial changes of these properties in the subsequent iterative cycles. Those changes on the molecular and $\pi$-planes are displayed in Figs. 3 and 4, respectively. The higher excitation effects were studied at the CISDTQ level with the 6-31G basis set, the spin properties did not change with the following iterative cycles. Even when other references were used, the energy and spin properties changed very slightly. Therefore it is reasonable to assume that the results obtained at this stage are very close to the full CI ones.

Another consequence of including higher excitations into the CI expansion is that the spin densities on the nuclear centres increase. This is clearly shown by the great changes of the spin densities at nitrogen, oxygen and hydrogen in dihydronitroxide from the CISD to CISDTQ. At $\mathrm{C}_{2 \mathrm{v}}$ geometry, the spin population on the nitrogen increases from 0.0846 to 0.1196 with $6-31 \mathrm{G}$ basis set; on the oxygen from 0.1682 to 0.2156 ; and on the hydrogen from -0.0093 to -0.0120 .

The addition of polarization functions to the 6-31G basis set adjusts the spin densities among the nuclei, slightly shifting spin population from the oxygen to the nitrogen atom; however, the major change happened to the spin densities on the nuclear centres. Contrary to the effect of electron correlation, the augmentation of the polarized basis set decreases the spin population on the nuclear centres. Since these two factors have opposite effects on the spin densities and would cancel each other at a certain stage, it is pos- 


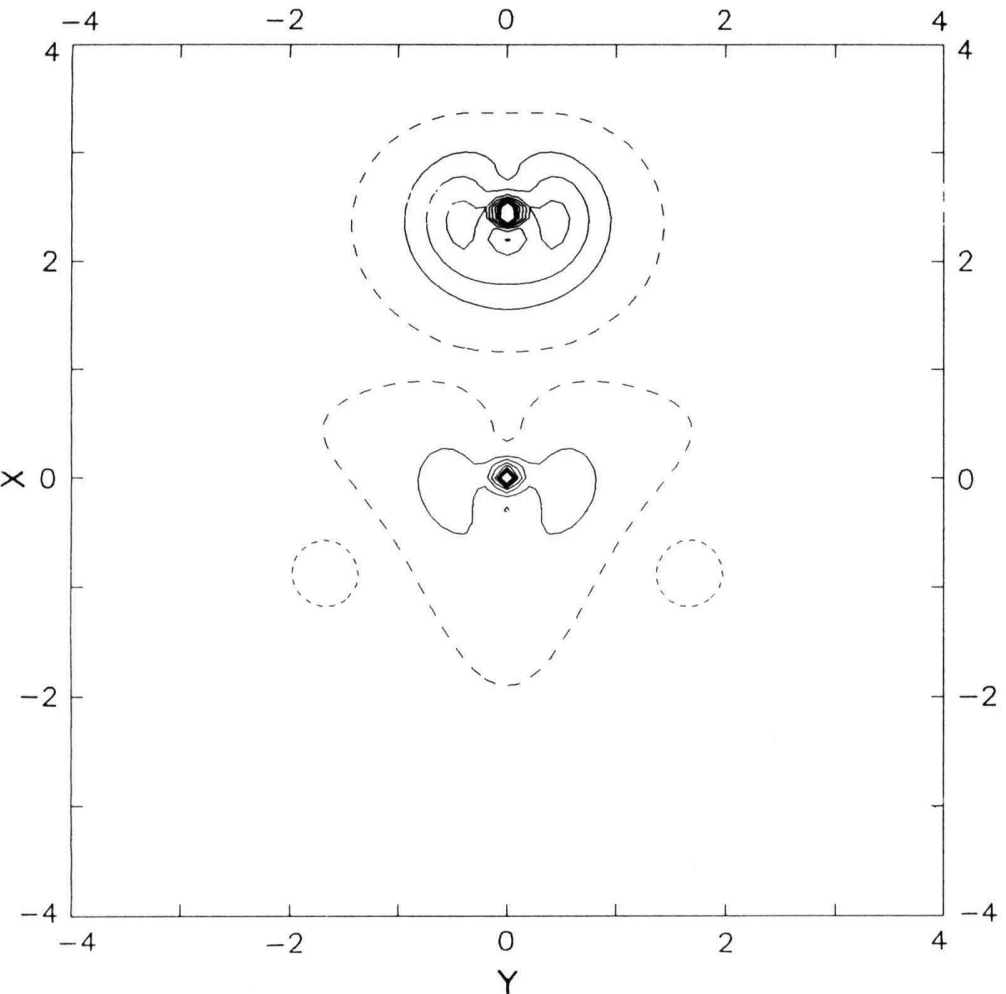

Fig. 1. Iterative CI spin densities in the molecular plane of $\mathrm{H}_{2} \mathrm{NO}$. Solid lines indicate positive values, dashed lines zero and dotted ones negative contours. Adjacent contours are separated by $0.005 e / a_{0}^{3}$.

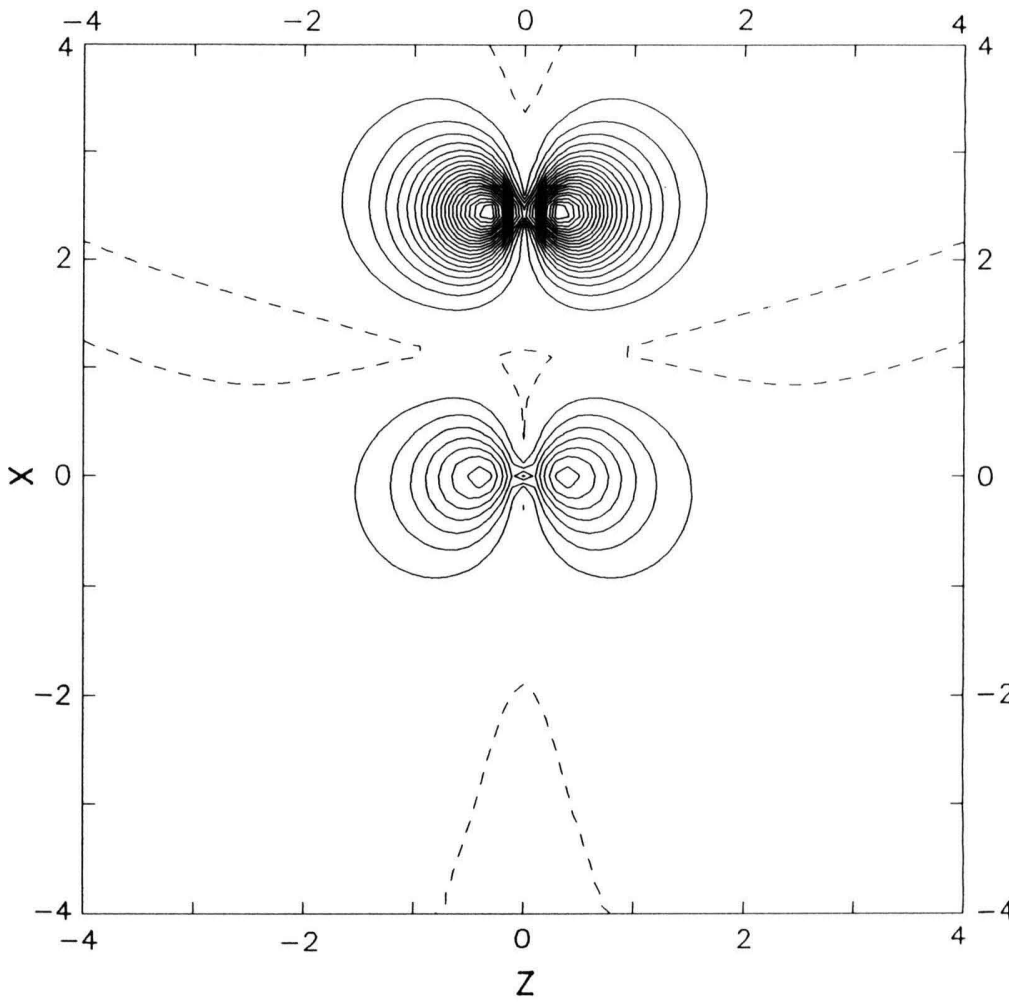

Fig. 2. Iterative CI spin density in the $\pi$-plane of $\mathrm{H}_{2} \mathrm{NO}$. Solid lines indicate positive values, dashed lines zero contours. Adjacent contours are separated by $0.02 e / a_{0}^{3}$. 


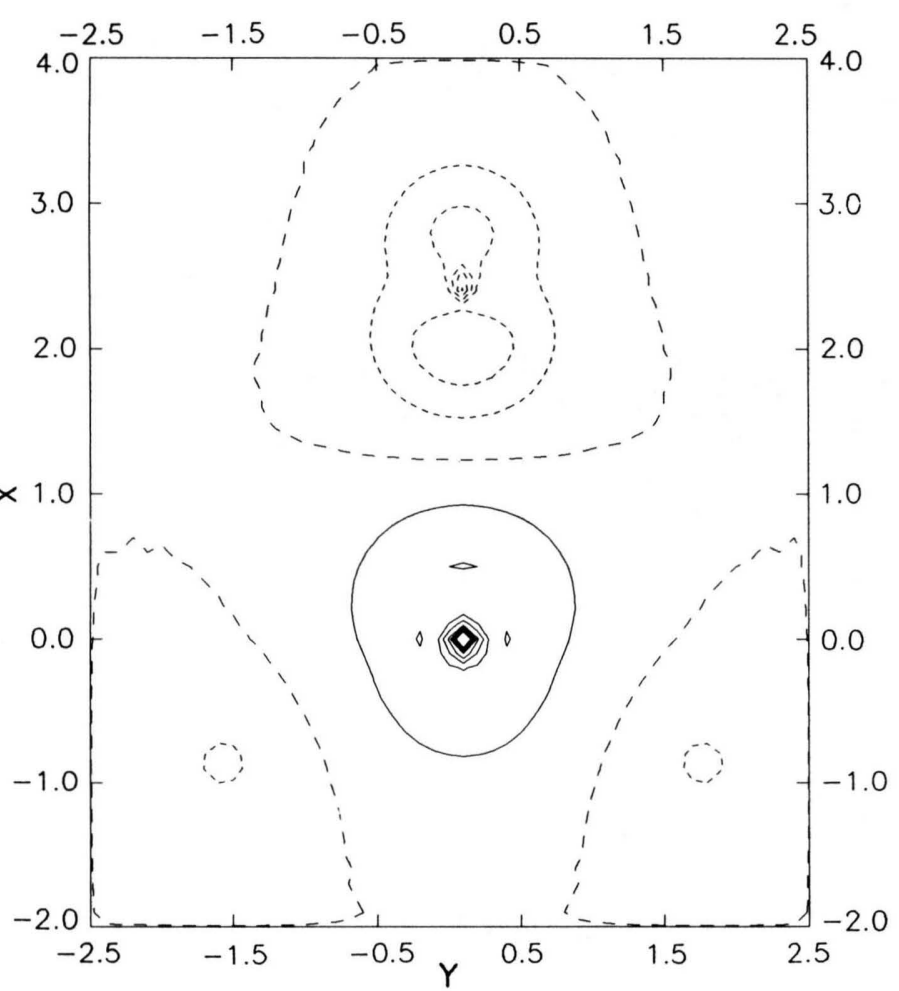

Fig. 3. Difference between iterative CI and SDCI spin densities in the molecular plane of $\mathrm{H}_{2} \mathrm{NO}$. Solid lines indicate positive values, dashed lines zero and dotted ones negative contours. Adjacent contours are separated by $0.001 e / a_{0}^{3}$.

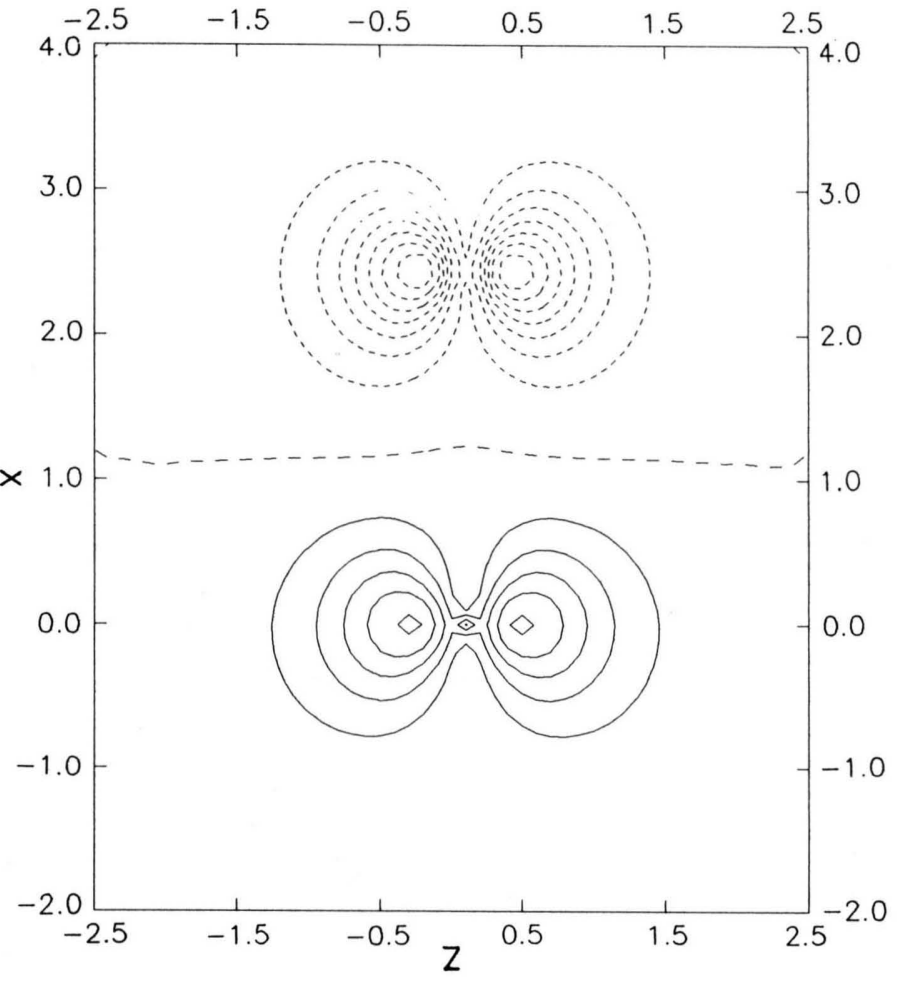

Fig. 4. Difference between iterative CI and SDCI spin densities in the $\pi$-plane of $\mathrm{H}_{2} \mathrm{NO}$. Solid lines indicate positive values, dashed lines zero and dotted ones negative contours. Adjacent contours are separated by $0.004 e / a^{3}$ 
sible to predict the Fermi contact term rather accurately without recourse to large-scale CI calculations. For instance, the iterative CI wavefunction with the 6-31G basis set predicts the Fermi contact terms of the nitrogen and hydrogen atoms with values of 0.0927 and -0.0078 , respectively, at the $\mathrm{C}_{s}$ geometry; the experimental quantities from ESR [1] are 0.0939 on the nitrogen and -0.0074 on the hydrogen atom, respectively. The difference is smaller than $6 \%$.

Also, the above discussion of the effect of higher excitations and basis-set quality on the Mulliken spin population will imply that accurate prediction of spin population throughout the whole molecule requires large-scale CI computations. Nevertheless, those configurations beyond quadruple excitation may not contribute to the spin distribution in a substantial manner. As demonstrated by the CISDTQ calculation of $\mathrm{C}_{2 \mathrm{v}}$ with 6-31G basis set, including single, double, triple and quadruple excitations into the $\mathrm{CI}$ expansion, shifts only about 0.02 from oxygen to nitrogen compared with the CISD treatment. Hence, it is reasonable to conclude that the Mulliken spin population of nitrogen would fall in the range $0.39-0.41$ and of oxygen in the range of $0.62-0.64$ with this particular basis set.

\section{2. $\left(\mathrm{CH}_{3}\right) \mathrm{HNO}$ and $\left(\mathrm{CH}_{3}\right)_{2} \mathrm{NO}$}

The substitution of the hydrogen atoms with methyl groups significantly changes the spin population in nitroxide radicals, similar to the earlier findings with the UHF [5] and the LSD [11] methods. From $\mathrm{H}_{2} \mathrm{NO}$ to $\left(\mathrm{CH}_{3}\right)_{2} \mathrm{NO}$, UHF with a $3 \mathrm{~s} 2 \mathrm{p} / 1 \mathrm{~s}$ basis set saw spin population changes of $\mathrm{N}+0.132$ and $\mathrm{O}-0.107$, respectively. The LSD predicts a 0.033 gain on $\mathrm{N}$ and a 0.109 loss on O with a DZV basis-set [11]. The present study shows +0.056 change for $\mathrm{N}$ and -0.104 for $\mathrm{O}$ at the $6-31 \mathrm{G}$ basis set. The changes appear to be systematic.

As demonstrated above, the iterative CI with a 6-31G basis set may produce the Fermi contact term with a relatively high precision. For monomethylnitroxide, we found a larger spin density on the nitrogen atom compared to that in the $\mathrm{H}_{2} \mathrm{NO}$ radical. Also the spin densities on the hydrogens from both the nitroxyl and axial positions of the methyl group were predicted closely; this finding differs from those of Gillon et al. [5], but fits the experiment quite well [2]. Our results on dimethylnitroxide also agree with the experiment fairly well. At the $\mathrm{C}_{2 \mathrm{v}}$ geometry, the theoret- ical spin densities of nitrogen and axial hydrogen atoms are predicted as 0.1205 and 0.0072 , respectively, compared to the values of 0.1322 and 0.0077 from the ESR experiment [2]. The calculated spin density on the oxygen atom is 0.1205 , only a little larger than the one on nitrogen. This is in agreement with the experimental picture from the PND [4] and close to the ESR data for di-sec-butylnitroxide [3].

The predicted Mulliken spin populations on nitrogen and oxygen become closer in dimethylnitroxide. Using the iterative CI wavefunction with the 6-31G basis set, the calculated Mulliken spin population is 0.43 on nitrogen, 0.56 on oxygen. If higher excitation effects were included, these two quantities would be very similar.

Electron correlation may be partitioned into dynamical and non-dynamical portions [22]. The dynamical correlation, found in all systems, is based on the idea of correlated electron motion. The non-dynamical part refers to the effects due to near-degeneracies and rearrangement of electrons within partially filled orbitals and is usually quite important in open-shell systems. The iterative CI technique has been shown to be a powerful approach to this non-dynamical correlation [23]. By taking natural orbitals instead of ROHF orbitals to form the reference wave function, the iterative CI method could improve the reference quality quite effectively by including most of the nondynamical correlations. The spin population partition of $\mathrm{N} / \mathrm{O}$ in dimethylnitroxide obtained from the ROHF reference is $0.27 / 0.70$ with the $6-31 \mathrm{G}$ basis set. This value changes to $0.40 / 0.55$ with the natural-orbitalconstructed reference and is quite close to that calculated from the whole CI expansions. It suggests that non-dynamical correlation is mainly responsible for the spin shift from oxygen to nitrogen.

\subsection{Spin Polarization Mechanism}

The spin polarization mechanism in the CI method has been investigated through a core calculation technique $[24,25]$. Only one orbital was allowed to be polarized under the unpaired electron. The results for $\mathrm{C}_{2 \mathrm{v}} \mathrm{H}_{2} \mathrm{NO}$ with the $3 \mathrm{~s} 2 \mathrm{p} / 1 \mathrm{~s}$ basis-set are summarized in Table 6. The simple summation of contributions from all the orbitals is comparable to the SCFSDCI results. The Mulliken spin population does not change much at this stage. This shows that electron correlation, more specifically dynamical correlation, contributes to the spin polarization in the CI scheme. 
Table 5. Total energies, spin densities, Mulliken spin populations and the number of configurations for $\left(\mathrm{CH}_{3}\right)_{2} \mathrm{NO}$ with the SDCI and Iterative CI treatments and various basis sets.

\begin{tabular}{|c|c|c|c|c|c|c|c|c|c|c|}
\hline \multirow[t]{2}{*}{ Basis set } & \multirow[t]{2}{*}{ Total energy } & \multicolumn{4}{|c|}{ Spin density } & \multicolumn{4}{|c|}{ Mulliken spin population } & \multirow{2}{*}{$\begin{array}{l}\text { No. of con- } \\
\text { figurations }\end{array}$} \\
\hline & & $\mathrm{N}$ & $\mathrm{O}$ & $\mathrm{C}$ & $\mathrm{H}_{a}$ & $\mathrm{~N}$ & $\mathrm{O}$ & $\mathrm{C}$ & $\mathrm{H}_{a}$ & \\
\hline \multicolumn{11}{|l|}{ SDCI } \\
\hline $\begin{array}{l}3 \mathrm{~s} 2 \mathrm{p} / 1 \mathrm{~s} \\
6-31 \mathrm{G}\end{array}$ & $\begin{array}{l}-208.2223322 \\
-208.7443292\end{array}$ & $\begin{array}{l}0.1150 \\
0.0798\end{array}$ & $\begin{array}{l}0.2358 \\
0.1343\end{array}$ & $\begin{array}{l}-0.0164 \\
-0.0107\end{array}$ & $\begin{array}{l}0.0053 \\
0.0055\end{array}$ & $\begin{array}{l}0.3459 \\
0.3411\end{array}$ & $\begin{array}{l}0.6694 \\
0.6550\end{array}$ & $\begin{array}{l}-0.0235 \\
-0.0237\end{array}$ & $\begin{array}{l}0.0079 \\
0.0129\end{array}$ & $\begin{array}{l}55337 \\
87497\end{array}$ \\
\hline \multicolumn{11}{|c|}{ Iterative $\mathrm{CI}$} \\
\hline $\begin{array}{l}3 \mathrm{~s} 2 \mathrm{p} / 1 \mathrm{~s} \\
6-31 \mathrm{G}\end{array}$ & $\begin{array}{l}-208.2230985 \\
-208.7456608\end{array}$ & $\begin{array}{l}0.1437 \\
0.1010\end{array}$ & $\begin{array}{l}0.2158 \\
0.1205\end{array}$ & $\begin{array}{l}-0.0188 \\
-0.0127\end{array}$ & $\begin{array}{l}0.0066 \\
0.0072\end{array}$ & $\begin{array}{l}0.4294 \\
0.4311\end{array}$ & $\begin{array}{l}0.5861 \\
0.5592\end{array}$ & $\begin{array}{l}-0.0278 \\
-0.0292\end{array}$ & $\begin{array}{l}0.0100 \\
0.0170\end{array}$ & $\begin{array}{l}55337 \\
87497\end{array}$ \\
\hline
\end{tabular}

Table 6. The spin densities obtained from the core calculations of $\mathrm{H}_{2} \mathrm{NO}$ with the ROHF orbitals and the $3 \mathrm{~s} 2 \mathrm{p} / 1 \mathrm{~s}$ basis set.

\begin{tabular}{lrrrrrrrrr}
\hline Centre & $1 \mathrm{a}_{1}$ & $2 \mathrm{a}_{1}$ & $3 \mathrm{a}_{1}$ & $4 \mathrm{a}_{1}$ & $5 \mathrm{a}_{1}$ & $1 \mathrm{~b}_{1}$ & $2 \mathrm{~b}_{1}$ & $1 \mathrm{~b}_{2}$ & Sum \\
\hline $\mathrm{N}$ & 0.00 & -0.02 & -0.03 & 0.11 & 0.00 & 0.00 & 0.00 & 0.00 & 0.06 \\
$\mathrm{O}$ & -0.09 & 0.00 & 0.23 & 0.12 & 0.04 & 0.00 & 0.00 & 0.00 & 0.30 \\
\hline
\end{tabular}

The UHF theory, allowing spin polarization in a different mechanism, could predict reasonable spin densities on nuclear centres if spin contamination was annihilated [6]. However, it is a very crude independent particle model like the ROHF and cannot account for the strong non-dynamical correlation in the systems and fails to predict the spin partitions adequately. In the LSD approximation, the exchange and correlation term is written in a local form [11]. Because of spurious self-interaction in this scheme, the exchange energy is underestimated by $10-15 \%$ and the correlation energy is overestimated by as much as $100-200 \%$ for atoms $[26,27]$. As a result, electrons with the same spin would prefer to stay away from each other $[28,29]$. With the self-interaction correction included, the exchange energies increase and the expectation values of $\langle r\rangle$ for valence orbitals decrease, and both are closer to the HF results [27]. However, this correction does not always bring the theoretical predictions closer to experiments. Actually, the discrepancies with experiment of inter-configurational energies tend to be larger when self-interaction correction has been used [30]. This can be tentatively interpreted as follows: the extra amount of self-interaction in the LSD approximation happens to have the same effects as the non-dynamical correlation, for which the HF theory cannot account, and in fact contributes to the successes of the LSD for the inhomogeneous-electron-gas systems [31]. The supe- riority of LSD over RHF and UHF in the strongly correlated (non-dynamical correlation) systems [32] supports these arguments. The LSD predicts a more accurate $\left\langle r_{12}^{-1}\right\rangle$ value than does the $\mathrm{HF}$ for $\mathrm{H}_{2}$ [33].

Recently, Jones and Gunnarsson $[34,35]$ conducted extensive studies on exchange energy behaviour. Their results show that, generally, the LSD approximation gives a satisfactory description of exchange differences, but for cases where the antibonding orbitals are occupied, the stabilities are overestimated. This, clearly, demonstrates the inadequacy of LSD. For molecular systems, the self interaction in the exchange term favours the orbital energies in different degrees. Generally speaking, it could bring extra stability for antibonding orbitals because the orbitals would be more diffuse; however, its consequences on excitation energies between orbitals are much more complicated $[34,35]$. As described above, the localized exchange term in the LSD approximation could account for the large non-dynamical correlation in CI theory (see [29]). Since non-dynamical correlation is crucial to a correct prediction of spin properties, the LSD approximation would behave much better than the UHF. This explains the same tendencies of the treatment by the iterative CI and LSD methods for the nitroxide radicals. The correlation term defined in LSD theory may be considered as the dynamic correlation portion in the CI approach. The small contribution of dynamical correlation to the spin shifts observed in the present CI calculations may rationalize the conclusion of Delley et al. [11] on electron correlation effects (see also [12]).

\section{Conclusion}

The present SCF-CI study shows the importance of basis-set quality and electron correlation in describing 
the spin populations in nitroxide radicals. The cancellation of the effects from higher excitations with that from improvement of basis-set quality makes it possible to predict the Fermi contact term at the iterative CISD level with the 6-31G basis set. Even though an accurate Mulliken spin population is computationally demanding, we still can predict it within a certain precision based on the extrapolation of spin population with excitation levels. The substitution effects have been clearly shown by the large accumulation of spin on the nitrogen atom; therefore, $\mathrm{H}_{2} \mathrm{NO}$ is not a suitable theoretical prototype for studying nitroxide radicals. The substantially larger changes that were observed among iteration sequences of dimethylnitroxide with respect to those of dihydronitroxide indicates that higher excitation effects would have a bigger contribution in the former systems. Inclusion of higher excitations into the CI expansion, combined with better basis sets, will further shift the spin population from oxygen to hydrogen and would therefore provide pictures in closer agreement with experiment.

[1] M. Jinguji, T. Imamura, H. Murai, and K. Obi, Chem. Phys. Lett. 84, 335 (1981).

[2] J. Q. Adams, S. W. Nicksic, and J. R. Thomas, J. Chem. Phys. 45, 654 (1966).

[3] J. C. Baird, J. Chem. Phys. 37, 1879 (1962).

[4] P. J. Brown, A. Capiomont, B. Gillon, and J. Schweizer, Mol. Phys. 48, 753 (1983).

[5] B. Gillon, P. Becker, and Y. Ellinger, Mol. Phys. 48, 763 (1983).

[6] B. Gillon and Y. Ellinger, Mol. Phys. 63, 967 (1988).

[7] B. Burton, T. A. Claxton, and Y. Ellinger, Computer Phys. Commun. 17, 27 (1979).

[8] F. Pauzat, H. Gritli, Y. Ellinger, and R. Suba, J. Phys. Chem. 88, 4581 (1984).

[9] R. Briere, T. A. Claxton, Y. Ellinger, P. Rey, and J. Laugier, J. Amer. Chem. Soc. 104, 34 (1982).

[10] A. Farazdel and V. H. Smith, Jr., unpublished.

[11] B. Delley, P. Becker, and B. Gillon, J. Chem. Phys. 80, 4286 (1984)

[12] P. J. Becker, in: Density Matrices and Density Functionals (R. M. Erdahl and V. H. Smith, Jr., eds.), Reidel, Dordrecht 1987, p. 517.

[13] B. Gillon and J. Schweizer, in: Molecules in Physics, Chemistry, and Biology (J. Maruani, ed.), Vol. 3. Kluwer, Dordrecht 1989, p. 111.

[14] C. F. Bender and E. R. Davidson, J. Phys. Chem. 70, 2675 (1966).

[15] E. R. Davisdon, in: MOTECC: Modern Techniques in Computational Chemistry (E. Clementi, ed.), ESCOM, Leiden 1990, p. 553.

[16] E. Clementi et al., Acta Physiol. Hung. 27, 493 (1969).

[17] W. J. Hehre, R. Ditchfield, and J. A. Pople, J. Chem. Phys. 56, 2257 (1972).

[18] P. C. Hariharan and J. A. Pople, Chem. Phys. Lett. 66, 217 (1972).
The LSD includes the large non-dynamical correlations in the independent-particle model and therefore provides a much better approach than the UHF method in the spin property calculation. However, one should not be overoptimistic about the LSD calculation. The inadequacy of the LSD is that it most likely overestimates the spin transfer from oxygen to nitrogen in nitroxide radicals. Besides, the LSD approximation, like UHF, suffers from a spin contamination problem. Even though several successful applications $[12,13]$ were reported, special caution has to be employed for new systems. Comparison with more sophisticated ab initio methods, such as the iterative CI, would be of great help.

\section{Acknowledgement}

This work has been supported by the National Sciences and Engineering Research Council of Canada. One of us (J.W.) wishes to thank the Queen's School of Graduate Studies and Research for a Graduate Fellowship.

[19] W. Kutzelnigg and V. H. Smith, Jr., J. Chem. Phys. 41, 896 (1964).

[20] W. Kutzelnigg and V. H. Smith, Jr., Int. J. Quantum Chem. 2, 531 (1968).

[21] V. H. Smith, Jr. and W. Kutzelnigg, Int. J. Quantum Chem. 2, 553 (1968).

[22] I. Shavitt, in: Methods of Electronic Structure Theory (H. F. Schaefer, III, ed.), Plenum Press, New York 1977, p. 189 and references therein.

[23] E. R. Davidson, Reduced Density Matrices in Quantum Chemistry, Academic Press, New York 1976, and references therein.

[24] K. Funken, B. Engels, S. D. Peyerimhoff, and F. Grein, Chem. Phys. Lett. 172, 180 (1990).

[25] B. Engels and S. D. Peyerimhoff, J. Phys. B 21, 3459 (1988).

[26] B. Y. Tong and L. J. Sham, Phys. Rev. 144, 1 (1966).

[27] J. P. Perdew and A. Zunger, Phys. Rev. B 23, 5048 (1981).

[28] J. P. Perdew, in: Density Functional Theory of ManyFermion Systems (S. B. Trickey, ed.), Academic Press, San Diego 1990, p. 113.

[29] M. R. Norman, Phys. Rev. 28, 3585 (1983).

[30] O. Gunnarsson and R. O. Jones, Solid State Commun. 37, 249 (1981).

[31] S. Manoli and M. A. Whitehead, Phys. Rev. A 38, 630 (1988).

[32] R. O. Jones, in: Ab Initio Methods in Quantum Chemistry (K. P. Lawley, ed.), Wiley, New York 1987, p. 413.

[33] O. Gunnarsson and B. I. Lundqvist, Phys. Rev. B 13, 4274 (1976).

[34] R. O. Jones and O. Gunnarsson, Phys. Rev. Lett. 55, 107 (1985).

[35] O. Gunnarsson and R. O. Jones, Phys. Rev. B 31, 7588 (1985). 